\title{
Editorial
}

\section{Economics of Agricultural and Food Markets}

\author{
Anthony N. Rezitis, ${ }^{1}$ José M. Gil, ${ }^{2}$ and Maria Sassi ${ }^{3}$ \\ ${ }^{1}$ Department of Business Administration of Food and Agricultural Enterprises, University of Western Greece, 2 G. Seferi Street, \\ 30100 Agrinio, Greece \\ ${ }^{2}$ CREDA-UPC-IRTA and Edifici ESAB, Parc Mediterrani de la Tecnologia, Esteve Terradas, Barcelona, Spain \\ ${ }^{3}$ Department of Economics and Management, University of Pavia, V. S. Felice, 5-27100 Pavia, Italy
}

Correspondence should be addressed to Anthony N. Rezitis; arezitis@uwg.gr

Received 10 February 2013; Accepted 10 February 2013

Copyright (C) 2013 Anthony N. Rezitis et al. This is an open access article distributed under the Creative Commons Attribution License, which permits unrestricted use, distribution, and reproduction in any medium, provided the original work is properly cited.

The agricultural and food sectors are very important components of economies around the world at national, regional, and global levels. Although production agriculture constitutes a very small percentage of the gross domestic product (GDP) in developed countries, the food system (incorporating the transportation, processing, distribution, and retailing of food products) represents a much higher percentage of the GDP. The main aim of this special issue is to publish highquality economic research investigating supply and demand issues related to the agricultural and food markets. This is because during recent decades there has been a significant change in various components of the world agricultural and food sectors. This special issue publishes six research articles related to issues such as commodity food prices, food price inflation, food production and ecocertified food markets, consumption and demand for particular goods, that is, milk and vegetables, and financial and economic risks due to the aflatoxin contamination of peanuts as follows.

(i) The article entitled "Commodity food prices: review and empirics" provides a literature review of studies examining the potential causes and consequences of recent surges in food and agricultural commodity prices and develops a structural time series model to analyze the behavior of the IMF monthly commodity food price index for the past 20 years. The empirical results indicate that commodity food prices present seasonality and cyclicality with the longest periodicity of two years, and the forecasts show high and volatile commodity food prices. (ii) The article entitled "Food price inflation rates in the euro zone: distribution dynamics and convergence analysis" examines the mean reversion attitude of food price inflation rates as well as the comovement of the inflation rates among different food subgroups in the Euro zone using nonparametric econometric methods. The results do not fully support the hypothesis of the food price inflation rates convergence for the whole period under investigation. Mean reversion shows up in different time periods and in different food categories.

(iii) The article entitled "Firm's decisions based on consumers' choices in ecocertified food markets" proposes a framework for examining whether a food production enterprise, attempting to build an ecocertification strategy, connects the creation of environmental value with the creation of economic value, balancing environmental sustainability with economic sustainability. An empirical investigation of the model using consumer data indicates that a variety of factors, such as consumer's age and profession, family's income and purchasing strategy, and product quality association in consumers' mind and the retailing outlet, play an important role in shaping the respondents' intention to pay for the producers' ecofriendliness.

(iv) The article entitled "A case study of probit model analysis of factors affecting consumption of packed and unpacked milk in Turkey" focuses on the effects of some sociodemographic factors, which influence the 
consumers' decision to purchase packed or unpacked fluid milk in Sivas, Turkey. The empirical results indicate that consumers with lower household size and higher income level tend to consume packed milk, while consumers sensitive to price are less likely to consume packed milk considering that packed milk price is expensive compared to unpacked milk price.

(v) The article entitled "Demand for fresh vegetables in the United States: 1970-2010" analyzes a demand system for eight major fresh vegetables in the USA using a first-differenced Linear Approximate Almost Ideal Demand System (LA-AIDS) to estimate price and expenditure elasticity of demand, imposing homogeneity and symmetry restrictions. The empirical findings indicate that consumers are not only responsive to changes in own prices, but they also respond significantly to changes in prices of other fresh vegetables consumed. Conditional budget share allocation to lettuce, cabbage, and celery has declined, while the share of the consumer dollar going to tomatoes, peppers, and onions has increased.

(vi) The article entitled "Economic risks of aflatoxin contamination in marketing of peanut in benin" examines the financial risk associated with sorting and storing of peanut and peanut products along the marketing chain. Study results show that the prices paid for peanut, prices received, the costs of sorting, and storage are dominant factors in reducing aflatoxin levels in peanut. Practices such as drying, sorting, and storing, however, pose financial risks in the market of peanut traders.

Anthony N. Rezitis José M. Gil Maria Sassi 

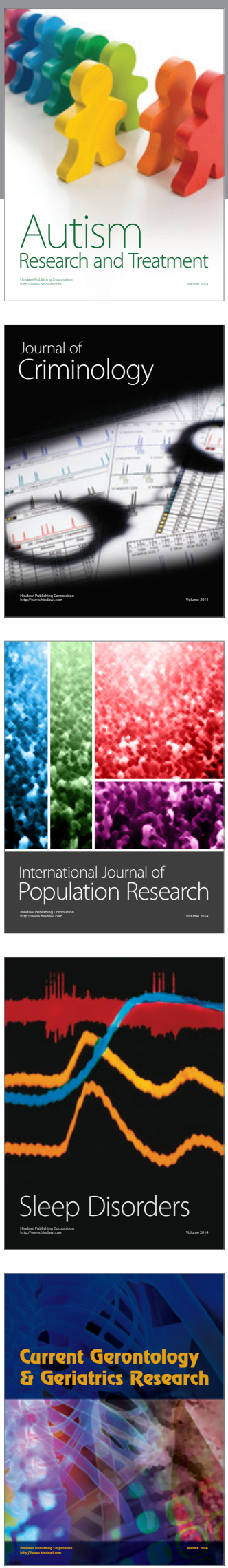
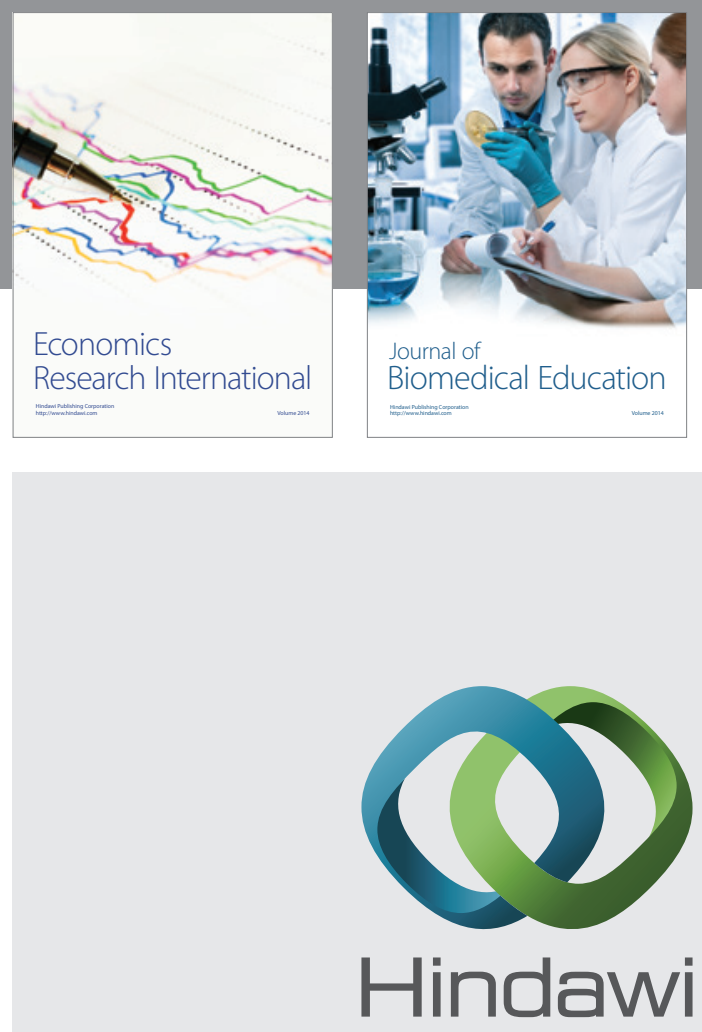

Submit your manuscripts at

http://www.hindawi.com
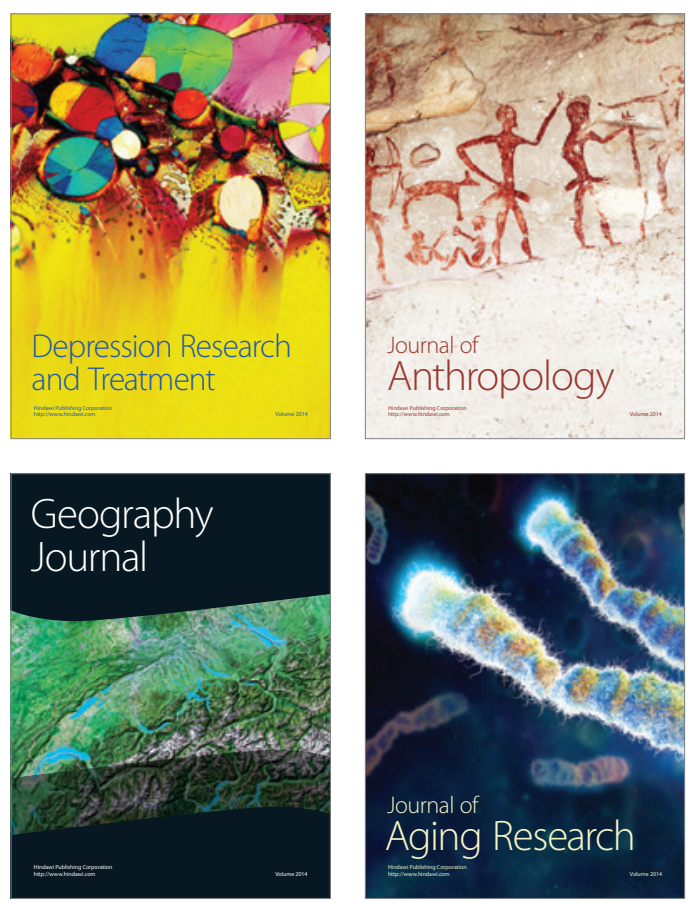
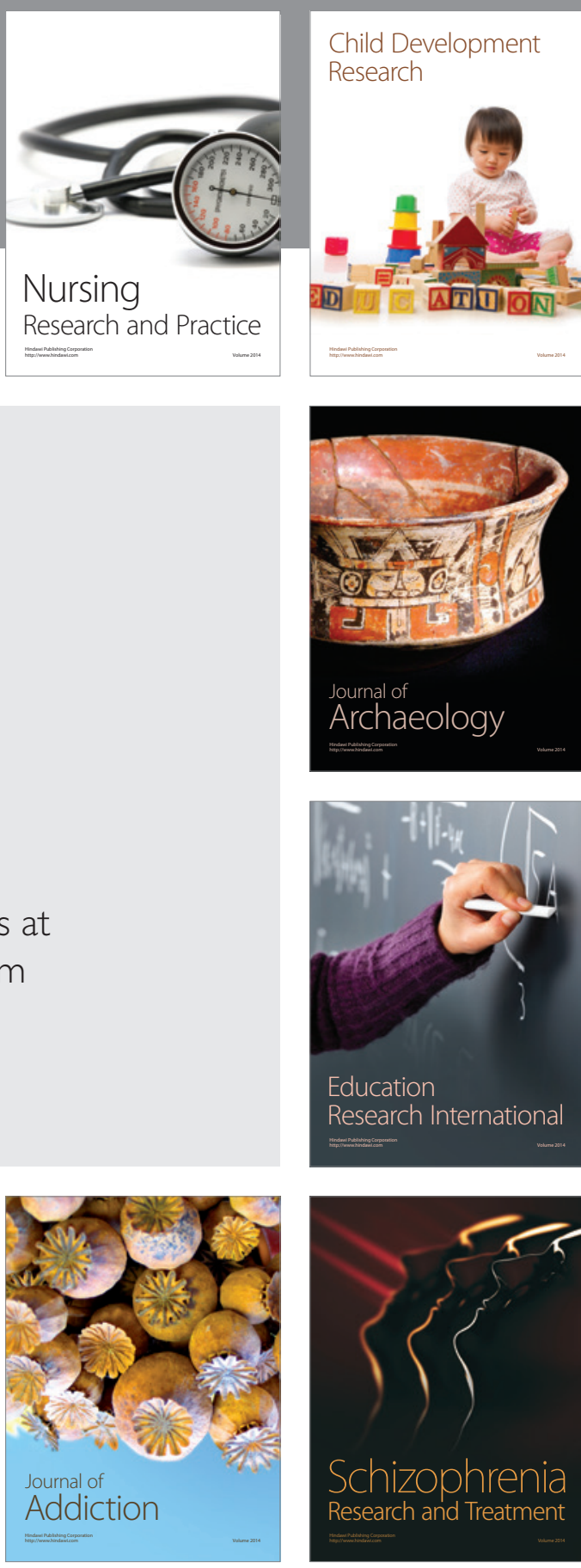

(D)
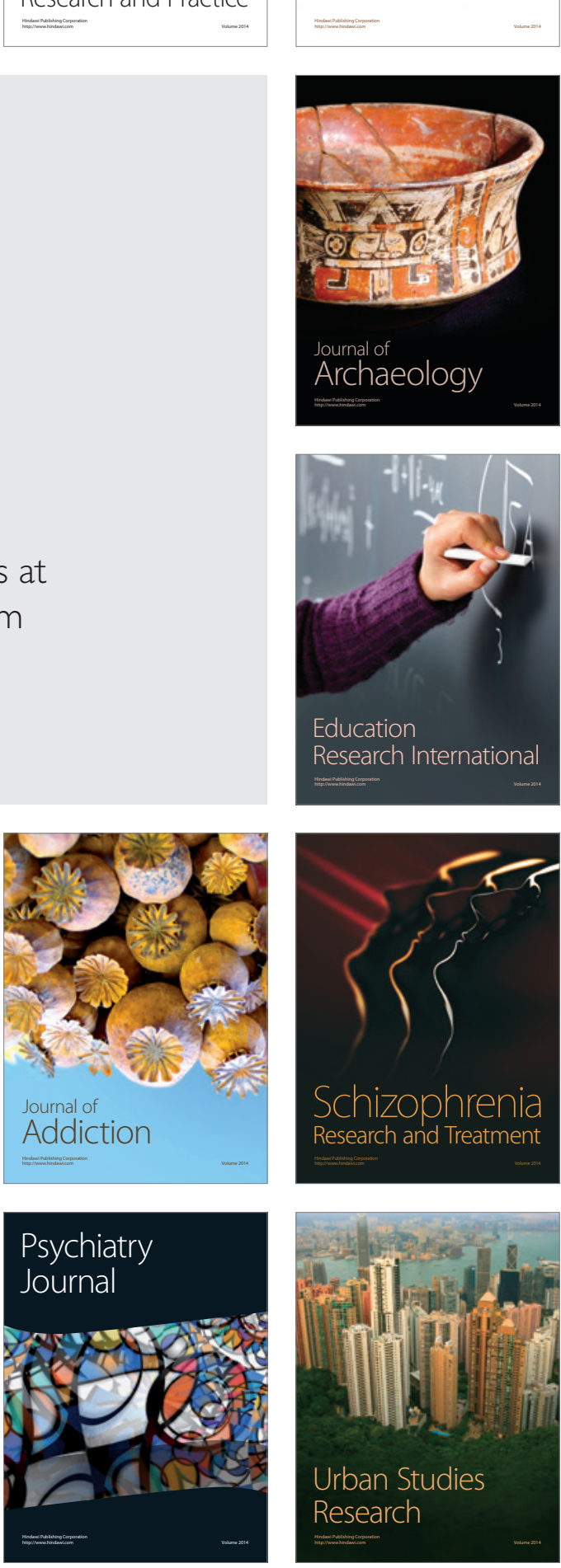